\title{
Clinical Research in Saudi Arabia: Trainee Knowledge and Attitude
}

\author{
Ziad Zekry, Moosa Khalifah, Joud Enabi, Hamza Enabi, Basel Alkhatib, and Albara Alsayed
}

\begin{abstract}
Background Clinical research is an integral part of medical and surgical residency programmes, as well as medical school.

Aim This study aimed to investigate attitudes toward, the experience of, and perceived barriers to, conducting clinical research in the medical and surgical fields in Saudi Arabia. We also aimed to explore attitudes toward article processing charges and submission fees.

Methods A cross-sectional study conducted in Saudi Arabia during the months of May-June 2021. The inclusion criteria were trainees in various medical and surgical specialities.

Results The majority of participants conducted at least one research project, representing $92.5 \%(n=185)$; of those, $77.3 \%$ $(n=143)$ had already published their research. While $33.5 \%$ $(n=67)$ of participants felt comfortable designing, leading and critically appraising articles, only $17.3 \%(n=34)$ were comfortable using statistical software. Barriers to clinical research include lack of personal interest, lack of interest on the part of programme directors/mentors, inadequate support from mentors/assistants, being overwhelmed with educational activities and examinations, lack of reward and/or motivation, and difficulties obtaining an appropriate sample.

Conclusion This article provides new insight into the knowledge of, and attitude toward, clinical research among Saudi Arabian trainees, and discusses the implications thereof and the future direction of clinical research in Saudi Arabia.
\end{abstract}

Index Terms - Clinical Research, Research during residency

\section{INTRODUCTION}

In recent years, research has become an essential component of several medical and surgical training specialities. With the overall aim of drawing appropriate scientific conclusions, research activities foster critical thinking and lifelong learning. Thus, health research training is an essential aspect of medical school, residency training programmes and fellowships.

As part of their training programmes, Saudi Arabian trainees have recently been mandated by the Saudi Commission for Health Specialties to conduct at least one research project before graduation; however, only $58 \%$ have complied with this mandatory requirement [1]. Although one study noted a favourable attitude toward research [2], several barriers emerged, including lack of research training/ curriculum, inadequate facilities, insufficient time, work-related stress, and a lack of supervisors [3]. Two of those factors - the lack of supervisors and the lack of a research curriculum in the training programme - were emphasised [1]. Still, the literature lacks

Ziad Zekry, Mossa Khalifah, Albara Alsayed are with Emergency Department, King Fahd Medical City, e-mail: Mossa.r.k@hotmail.com, e-mail: Ziad.wz@hotmail.com, e-mail: asaalsayed@kfmc.med.sa

Joud Enabi, Hamza Enabi, Basel Alkhatib are with Alfaisal University , e-mail: jenabi@alfaisal.edu, e-mail: henabi@alfaisal.edu, e-mail: Balkhatib@alfaisal.edu exploration of the trainees' competencies toward research mainly whether trainees are competent to conduct studies and appraise articles.

The purpose of this study was to investigate attitudes toward, the experience of, and perceived barriers to, conducting clinical research in Saudi Arabian medical and surgical training programmes. Moreover, we were unable to establish from the literature what constitutes "fair" article processing charges and submission fees from the trainees' perspective. Therefore, we aimed to explore attitudes toward article processing charges and submission fees.

\section{METHODS}

This is a cross-sectional study carried out in Saudi Arabia during the months of May-June 2021. The inclusion criteria were trainees in various medical and surgical specialities. The data were collected via a structured survey, using an online survey tool; the survey was developed by the authors and distributed via social media. The first part consists of questions about demographics; participation in research; and familiarity with the journal submission process, data analysis and statistical software such as SPSS or STATA. Part Two is concerned with barriers to conducting clinical research, while Part Three inquires about fees for article submission and what constitutes a fair amount to pay. We excluded those whose survey response was incomplete.

\section{RESULTS}

\section{Demographic}

The total number of participants was 200; the participants' demographics are illustrated in Table 1.

\section{Design, submission and publishing}

The majority of the trainees conducted at least one research project, representing 92.5\% $(\mathrm{n}=185)$; of those, $77.3 \%(\mathrm{n}=143)$ had already published their research. Almost two thirds submitted their research to the journal independently, representing $70.8 \%(\mathrm{n}=131)$. However, the percentage of those who feel comfortable designing, leading or critically appraising articles was only $33.5 \%(n=67)$ of all participants, and only $17.3 \%$ $(n=34)$ were capable of conducting data analysis using statistical software such as SPSS or STATA.

The majority of participants conducted cross-sectional studies $-47 \%(\mathrm{n}=94)$; followed by case reports $-15.5 \%(\mathrm{n}=31)$; and cohort studies $-15.5 \%(\mathrm{n}=31)$. Review articles were written by $9.5 \%(\mathrm{n}=19)$, while case-control and clinical trials each comprised only $6 \%(n=12)$. Case series were reported by only one participant $-0.5 \%(\mathrm{n}=1)$. 
TABLE I

PARTICIPANTS'DEMOGRAPHICS

\begin{tabular}{ll}
\hline $\begin{array}{l}\text { Variables } \\
\text { Age }\end{array}$ & Percentage (n) \\
18-24 years & $11(22)$ \\
25-27 years & $47.5(95)$ \\
Older than 27 years & $41.5(83)$ \\
Gender & \\
Male & $44.5(89)$ \\
Female & $55.5(111)$ \\
Educational level & \\
Intern & $18.3(36)$ \\
Resident & $62.4(123)$ \\
Registrar or specialist & $19.3(38)$ \\
\hline
\end{tabular}

\section{Barriers to conducting research}

Upon exploring the barriers to conducting research, the participants reported a lack of acknowledgement, difficulty getting their article published, difficulty accessing data and getting approval, lack of statistical or financial support, deficiencies in research proficiency and in the research curriculum, lack of interest from the supervisors themselves, and lack of interest and time constraints on the part of the trainees. Figure 1 illustrates the percentage prevalence of these factors.

Furthermore, predictors for uncomfortableness in designing, leading and critically appraising a study revealed five statistically significant variables. These include a lack of personal interest, inadequate support from mentors/assistants, being overwhelmed with educational activities and examinations, lack of reward and/or motivation, and difficulties obtaining an appropriate sample. Table 2 illustrates the inferential statistical tests and their $\mathrm{p}$-value for each variable.

\section{Article processing charge and publication fee}

Half the participants, $51.5 \%(\mathrm{n}=103)$, had never paid an article processing charge or publication fee directly to the journal. $27 \%(\mathrm{n}=54)$ reported paying less than $\$ 500 ; 16 \%$ $(n=32)$ paid less than $\$ 1000$; whereas $5.5 \%(n=11)$ of participants reported paying an amount higher than $\$ 1000$. When we inquired further as to what is considered a reasonable fee, $76 \%(\mathrm{n}=149)$ believed $\$ 100-\$ 500$ to be an acceptable rate, while $5.5 \%(\mathrm{n}=11)$ believed publications should be free of charge.

\section{DISCUSSION}

In this study, most participants conducted at least one research project. This percentage is higher than previously reported [1], indicating more research engagement. Interestingly, descriptive studies were the leading research design, of which cross-sectional and case-report studies were the most common.

Furthermore, we noted that only one-third of participants were comfortable designing and leading studies. This raises the question as to whether other experimental designs were perceived as challenging from a knowledge deficiency point of view or due to lack of supportive infrastructure; those two factors were indeed reported as barriers to conducting research.

The predictors for uncomfortableness in designing, leading or critically appraising a study include variables related to the trainees themselves and those related to the training programmes. The former include lack of personal interest, being overwhelmed with educational activities and examinations, and lack of reward. The latter, meanwhile, include a lack of interest in research in general, and a lack of support from mentors. Therefore, emphasis should be placed on the role of mentors and programme directors in motivating residents to become involved in research activity. This can be accomplished by allowing time for a research symposium, allocating time purely for research, and collaborating with research scientists for teaching and guidance.

Residents and interns also reported the lack of a research curriculum, which emerged as a predictor for not designing and leading research projects. We believe research knowledge among trainees requires attention. The large number of publications should not be used as a surrogate marker for increasing quality of education, as was once suggested [4]. Perhaps the reduced number of publications suggests the need for more research-oriented training programmes [5]; nonetheless, monitoring of productivity should be centralised and reported annually by the Saudi Commission for Health Specialties. Monitoring should include the study design, the sample size and the productivity based on the programme, institution and province. A centralised monitoring body should also include the medical schools and the Saudi trainees abroad.

We propose having multiple research blocks with didactic lectures on statistics, as advocated by one study [6]. A structured research curriculum is required in every training programme, and the already-established curriculum should be re-examined, particularly as medical students cited inadequate formal research training as a barrier [7]. Furthermore, the unavailability of samples might suggest insufficientknowledge about participant recruitment or appropriate data-gathering methods, or a lack of community awareness. The latter was also noted in previous studies [8], [9].

Our study also provides insight into what is perceived as fair with regard to article processing charges and publication fees in general. Charges vary significantly between journals and between countries. The average amount paid to journals was $\$ 2732$, with a range between $\$ 1620$ and $\$ 3662$ [10], [11]. This amount is considered unreasonable among our trainees; the majority believed $\$ 500$ to be an acceptable upper limit.

Volunteer bias might have overestimated the result of this analysis. A further large-scale analysis is needed to confirm or refute our findings. 
Lack of Acknowledgment for contribution to research

Difficulty publishing research

Poor database accessibility/poor access to database

Difficulty following up study subjects

Unavailability of samples

Difficulty obtaining study approval

Lack of allocated research time

Inadequate financial support

Lack of statistical support

Inadequate research training

Difficulty obtaining a research supervisor

Lack of a research curriculum

Inadequate support from mentors/assistants

Lack of reward and/or motivation

Other personal commitments such as marriage, work or family

lack of team work among participants

Inadequate facilities for research

Lack of time due to educational activities and examinations

Lack of interest
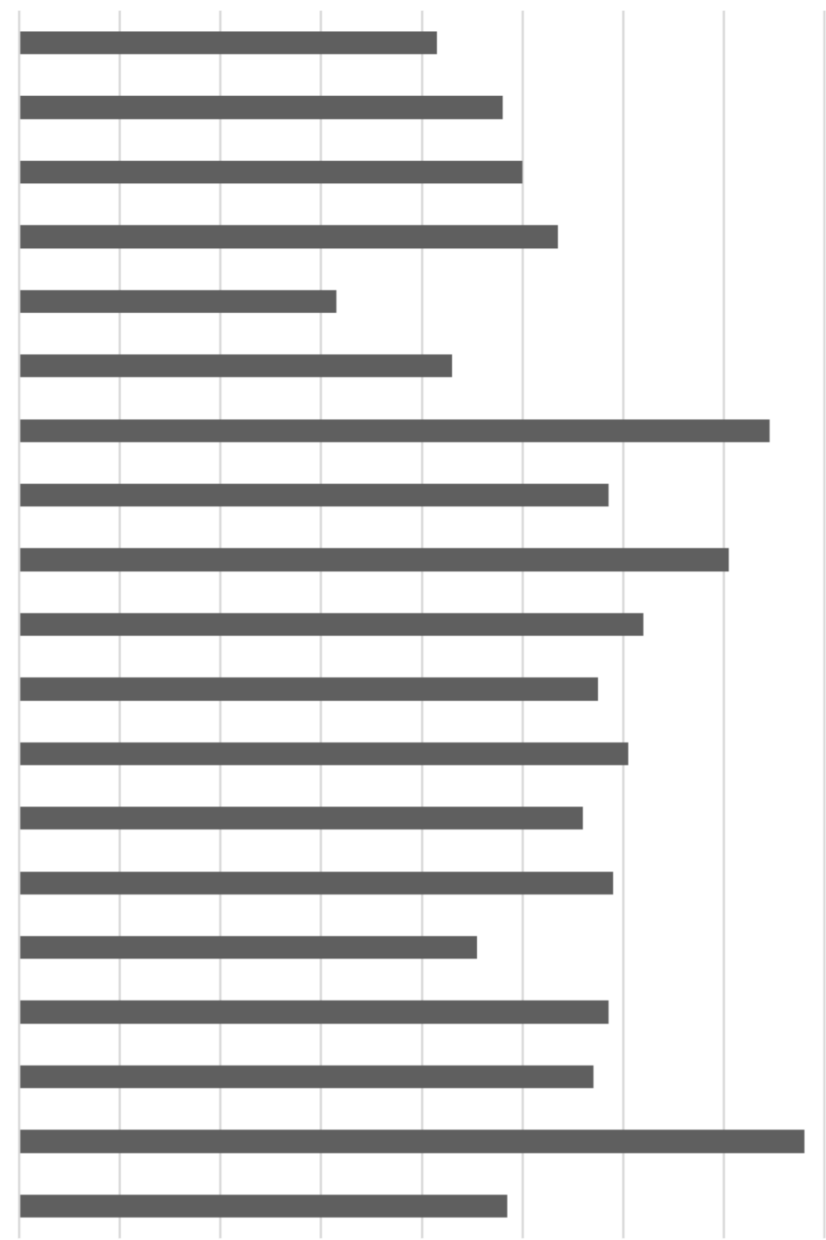

0

10

20

30

40

50

60

70

80

90

Fig. 1. Barriers to conducting research in Saudi Arabia, as reported by the participants

TABLE II

VARIABLES ASSOCIATED WITH UNCOMFORTABLENESS IN DESIGNING, LEADING AND CRITICALLY APPRAISING A STUDY

\begin{tabular}{lll}
\hline Variables & t-test (df) & p-value \\
Lack of interest & $2.37(198)$ & 0.019 \\
Lack of time due to the burden of educational activities, including examinations & $3.49(99.6)$ & 0.001 \\
Inadequate facilities for research & $1.37(198)$ & 0.173 \\
Lack of teamwork among participants & $1.34(198)$ & 0.180 \\
Other personal commitments such as marriage, work or family & $1.95(198)$ & 0.053 \\
Lack of reward and/or motivation & $2.39(116)$ & 0.019 \\
Inadequate support from mentors/assistants & $2.24(115)$ & 0.027 \\
Lack of a research curriculum & $1.49(198)$ & 0.136 \\
Difficulty obtaining a research supervisor & $1.91(116)$ & 0.059 \\
Inadequate research training during medical training or med school & $1.63(198)$ & 0.104 \\
Lack of statistical support & $-0.21(198)$ & 0.837 \\
Inadequate financial support & $-1.14(198)$ & 0.256 \\
Lack of allocated research time & $-0.49(198)$ & 0.625 \\
Difficulty obtaining study approval & $-0.13(198)$ & 0.897 \\
Unavailability of samples (or patients) & $2.73(198)$ & 0.007 \\
Difficulty following up study subject (or patients) & $-0.71(198)$ & 0.477 \\
Poor access to database & $0.29(198)$ & 0.766 \\
Difficulty publishing research & $0.11(198)$ & 0.910 \\
Lack of acknowledgement for contribution to research & $1.77(198)$ & 0.078 \\
\hline
\end{tabular}




\section{CONCLUSION}

This article provides new insight into the knowledge of, and attitude toward, clinical research among Saudi Arabian trainees. We noted an improvement in the percentage of those conducting research, although the knowledge of study design, analysis and publishing is still far from acceptable. More effort should therefore be directed toward clinical research training during residency, with an emphasis on more experimental studies.

\section{REFERENCES}

[1] Soubhanneyaz AA, Salem KA, Al-Dubai SAR. Perceptions, barriers, and practice of medical research of family medicine residents in Medina, Saudi Arabia. J Family Community Med. 2019 Sep-Dec;26(3):227-231. doi: 10.4103/jfcm.JFCM_38_19. PMID: 31572055; PMCID: PMC6755763.

[2] Al-Arifi MN. Attitudes of pharmacy students to- wards scientific research and academic career in Saudi Arabia. Saudi Pharm J. 2019 May;27(4):517-520. doi: 10.1016/j.jsps.2019.01.015. Epub 2019 Jan 17. PMID: 31061620; PMCID: PMC6488809.

[3] Saud AlEnazi A, Alamri AS, AlGhamdi AS, Alman- sour AH, Rubaian NFB, Al-Otaibi FK, Alreshaid FT, Saad Alaftan M, Esam Himdy Z, Makhdom RA, Alshahrani M. Perceptions, barriers, and attitudes toward research among in-training physicians in Saudi Arabia: A multicenter sur- vey. Sci Prog. 2021 AprJun;104(2):368504211010604 d doi: 10.1177/00368504211010604. PMID: 33970049.

[4] Ul Haq I, Ur Rehman S, Al-Kadri HM, Farooq RK. Research Productivity in the Health Sciences in Saudi Arabia: 2008-2017. Ann Saudi Med. 2020 Mar-Apr;40(2):147-154. doi: 10.5144/02564947.2020.147. Epub 2020 Apr 2. PMID: 32241169; PMCID: PMC7118236.

[5] Jahan S, Al-Saigul AM. Primary health care research in Saudi Arabia: A quantitative analysis. Int J Health Sci (Qassim). 2017 Apr-Jun;11(2):9-15. PMID: 28539857; PM- CID: PMC5426411.

[6] Mayo MJ, Rockey DC. Development of a success- ful scholarly activity and research program for subspecialty trainees. The American Journal of the Medical Sciences. 2015 Sep;350(3):222-7.

[7] Smith E, Haustein S, Mongeon P, Shu F, Ridde V,Larivière V. Knowledge sharing in global health research

- the impact, uptake and cost of open access to scholarly literature. Health Res Policy Syst. 2017 Aug 29;15(1):73. doi: 10.1186/s12961-017-0235-3. PMID: 28851401; PMCID: PMC5576373.

[8] Al-Rawashdeh N, Damsees R, Al-Jeraisy M, Al Qasim E, Deeb AM. Knowledge of and attitudes toward clinical trials in Saudi Arabia: a cross-sectional study. BMJ Open. 2019 Oct 22;9(10):e031305. doi: 10.1136/bmjopen-2019-031305. PMID: 31641002; PMCID: PMC6830621.

[9] Al-Jumah M, Abolfotouh MA, Alabdulkareem IB, Balkhy HH, Al-Jeraisy MI, Al-Swaid AF, Al-Musaaed EM, Al-Knawy B. Public attitude towards biomedical research at outpatient clinics of King Abdulaziz Medical City, Riyadh, Saudi Arabia. East Mediterr Health J. 2011 Jun;17(6):536-45. PMID: 21796973.
[10] Al-Hilali SM, Al-Kahtani E, Zaman B, Khandekar R, AlShahri A, Edward DP. Attitudes of Saudi Arabian Undergraduate Medical Students towards Health Research. Sultan Qaboos Univ Med J. 2016 Feb;16(1):e68-73. doi: 10.18295/squmj.2016.16.01.012. Epub 2016 Feb 2. PMID: 26909216; PMCID: PMC4746046.

[11] Morey CC. The Journal of Cognition after One Year: A Modern, Society-Backed, Fair Open-Access Option for Cognitive Psychology and Cognitive Neuroscience. J Cogn. 2019 Jan 24;2(1):1. doi: 10.5334/joc.54. PMID: 31517219; PMCID: PMC6634356. 